\title{
HADIRNYA MUSIK GONG PERUNGGU DALAM UPACARA ADAT KENDURI SKO PADA MASYARAKAT KERINCI PROVINSI JAMBI
}

\author{
Oleh: \\ Deria Sepdwiko \\ (Dosen FKIP Program Studi Pendidikan Sendratasik Universitas PGRI Palembang)
}

\begin{abstract}
ABSTRAK
Penelitian ini dilakukan bertujuan untuk mengungkapkan musik Gong Perunggu dalam upacara Kenduri Sko pada masyarakat Kerinci tepatnya di Dusun Empih Kecamatan Sungai Bungkal Kota Sungai Penuh. Jenis penelitian ini adalah penelitian kualitatif dengan metode menginterprestasikan. Objek penelitian ini adalah musik Gong Perunggu dalam upacara Kenduri Sko. Data dikumpul melalui studi pustaka, observasi, wawancara, dan dokumentasi. Analisa data dilakukan dengan berpedoman pada tehnik etnografi.Temuan hasil penelitian menyatakan bahwa musik Gong Perunggu merupakan alat musik ritual upacara Kenduhai Sko bagi masyarakat Kota Sungai Penuh. Musik Gong Perunggu mulai jarang digunakan sebagai kesenian tradisi disebabkan oleh tokoh adat, sehingga musik tersebut hanya boleh di bunyikan pada upacara Kenduhai Sko, menjadi kurang diminati oleh generasi muda.
\end{abstract}

Kata kunci : GongPerunggu, Ritual, Kenduri Sko.

\section{A. PENDAHULUAN}

\section{a) Latar Belakang}

Kerinci merupakan salah satu subkultur yang memiliki kekhasan budaya seperti suku-suku yang lainnya. Kespesifikan budaya yang dimiliki masyarakatnya merupakan sumbangan berharga terhadap kekayaan budaya masyarakat Indonesia. Salah satu produk budaya masyarakat Kerinci dengan kespesifikannya adalah musik Gong Perunggu yang selalu tampil dalam ritual adat Kenduri Sko. 
Gong Perunggu merupakan alat musik tradisional terbuat dari logam/perunggu dan memiliki dua buah warna bunyi. Warna bunyi ini diistilahkan oleh masyarakat setempat dengan bunyi gong jantan dan bunyi gong betina, sedangkan cara memainkannya dipukul dengan stick. Musik Gong Perunggu ini merupakan musik peninggalan nenek moyang masyarakat Kerinci yang memiliki latar belakang sejarah dan tercermin dalam adat istiadat dan pandangan hidup masayarakat dengan falsafah alam takambang jadi guru. Sejalan dengan hal tersebut Hamka menjelaskan bahwa konsep alam takambang jadi guru Bermakna bahwa segala sesuatu yang dicerminkan oleh alam mempunyai keterkaitan dan memiliki arti dalam kehidupan manusia dan kemudian diterapkan dalam kehidupan masyarakat (1984:83).

Musik Gong Perunggu ini difungsikan sebagai alat musik tradisional untuk pengantar sebelum upacara Kenduri Sko dilaksanakan, dalam bahasa kerincinya Ngejun Arah (meminta izin kepada lembaga adat untuk melakukan Kendururi Sko), (Wawancara tokoh adat Rio. 20 Mai 2013 di Dusun Empih). Setelah musik Gong Perunggu dimainkan barulah, masyarakat melaksanakan upacara ritual adat, Kerena Apa bila Gong Perunggu dibunyikan sebelum diacara Kenduri Sko maka masyarakat Dusun Empih akan mendapatkan sangsi berupa denda satu ekor sapi dan denda adat yang disepakati oleh lembaga adat.

Tanpa adanya musik Gong Perunggu ditengah-tengah masyarakat maka tidak bermakna upacara Kenduri Sko. Dengan adanya musik Gong Perunggu barulah masyarakat diizinkan oleh tokoh-tokoh Adat untuk pembersihan benda-benda pusaka yang sudah diambil dari tempat tertentu dikumpulkan, kemudian dimantrai oleh orang yang dipercayai dalam lembaga adat yaitu Samsir, seorang tokoh adat Dusun Empih yang dituakan dalam lembaga adat dan dipercayai untuk membaca mantra upacara Kenduri Sko.

Kenduri Sko adalah suatu upacara adat oleh masyarakat Kerinci dimaknai sebagai ritual kepercayaan yang bertujuan untuk membersihkan benda-benda pusaka seperti keris, rambut sehelai (rambut nenek moyang), kuju (tombak), baju besi, gong perunggu, dan gendang yang diletakkan pada tempat yang tidak bisa dilihat orang ( di atas loteng umoh g'deang ). Dalam upacara Kenduri Sko ini masyrakat bisa menyaksikan banyak keajaiban fenomena dalam pembersihan benda-benda pusaka, dalam hal ini Gong 
Perunggu memiliki peranan penting untuk mensahkan upacara pembersihan benda-benda pusaka tersebut.

Makna dalam lingkup estetika secara konvensional menurut Agus Sahcahari (2006: 93) sering dimengerti menjadi tiga kelompok besar, pertama makna psikologis, yaitu upaya untuk meningkatkan kualitas batin umat manusia perenungan akan kemahabesaran Tuhan dan perjuangan Nenek moyang mereka mempertahankan D'seung (Dusun), kedua makna instrumental, yaitu sebagai bagian dalam menyelenggarakan kehidupan ragawinya melalui ekspresi dalam memainkan musik Gong Perunggu atau sertaan dalam pembersihan benda-benda kebutuhan sehari-hari, ketiga, makna yang dimiliki oleh estetika itu sendiri dalam mewujudkan eksistensinya.

Dengan demikian dapat dikatakan bahwa pemaknaan dinilai sebagai suatu cara yang paling objektif untuk memberi arti dalam semua pekerjaan estetik, karena tanpa makna, apapun yang dikerjakan oleh manusia sama dengan "tiada". Namun pada kenyataan saat ini alat musik Gong Perunggu mulai jarang dipergunakan sebagai kesenian tradisi maupun sebagai musik pengiring tari, hal ini disebabkan oleh pengaruh musik elektro yang semakin marak berkembang di daerah Kerinci sehingga mengakibatkan masyarakat lebih cendrung memilih musik elektro sebagai musik pengiring tari dan hiburan. Berkaitan dengan hal di atas, Yunus (1990:31) menyatakan:

Penyebab surutnya minat masyarakat terhadap kesenian tradisional bersumber dari dua faktor yaitu faktor ekstern dan faktor intern. Faktor-faktor ekstern sebetulnya dapat di bending apabila faktor intern (dari) pemiliknya dapat diatasi. Faktor yang datang dari dalam adalah: (1) menurunya apresiasi masyarakat terhadap seni pertunjukan tradisional dan (2) kurangnya perhatian, dangkalnya pengetahuan dan pemahaman para pemangku adat, pemegang otoritas bidang kebudayaan di daerah-daerah terhadap produk budi, rasa dan karya masyarakat.

Melihat fenomena di atas, besar kemungkinan alat musik Gong Perunggu akan lenyap dari tengah-tengah masyarakat Kerinci. Hal ini merupakan kerugian yang besar bagi masyarakat pendukungnya, jika kepunahan tersebut terjadi maka para generasi selanjutnya tidak akan mengenal kebudayaan asli mereka. 


\section{b) Konsep Musik}

Pengertian musik dalam Kamus Besar Bahasa Indonesia Musik adalah: ilmu atau seni menyusun nada atau suara diutarakan, kombinasi dan hubungan temporal untuk menghasilkan komposisi suara yang mempunyai keseimbangan dan kesatuan, nada atau suara yang disusun sedemikian rupa sehingga mengandung irama, lagu dan keharmonisan (terutama yang dapat menghasilkan bunyi-bunyi itu) (1990:602).

Musik secara umum terbagi dua yaitu musik vokal dan musik instrumental Musik vokal dan musik instrumental, (1984:2). Pono Banoe menyatakan musik vokal lahir dari adanya usaha manusia untuk berkomunikasi sesamanya dengan cara memanggil-manggil dari jarak yang tidak dekat, tidak terjangkau oleh tangan untuk menyentuh lawan komunikasinya, sedangkan musik instrumental timbul dari adanya upacara-upacara yang bersifat magis guna mendapatkan sesuatu yang diharapkan dari makhluk atau benda yang didewa-dewakan".

Pada tahap berikutnya manusia sudah berpaling kepada alam dan lingkungannya, dengan menggunakan benda-benda alam dengan kondisi yang masih murni sebagai alat musik. Dari perkermbangan ini, maka lahirlah alat musik yang dinamakan alat musik Primitif, sampai menuju alat musik yang modern seperti sekarang ini. Dari asal usul dan perkembangan musik di atas dapat disimpulkan bahwa alat musik yang terdapat di setiap daerah berasal dari alam dan lingkungan manusia itu sendiri. Demikian juga halnya dengan alat musik Gong Perunggu yang terdapat di Kota Sungai Penuh. Yang lahir ditegah-tengah masyarakat pendukungnya sebagai budaya leluhur mereka yang disebut dengan musik tradisional yang memiliki ciri khas tersendiri dipergunakan sebagai sarana dalam upacara Kenduhai Sko bagi masyarakat pendukungnya.

\section{Unsur-Unsur Musik}

Menurut Sach menegaskan bahwa alat musik yang pertama kali dikenal adalah badan manusia itu sendiri atau anggota tubuh. Tepukan tangan, hentakan kaki atau

pukulan-pukulan terhadap anggota badan lainnya adalah merupakan pengiring ritmik yang sangat berperan. Lahirlah unsur-unsur musikal sebagai teori musik dasar yaitu Irama, Tempo, Melodi, Dinamik, Harmoni, bentuk atau struktur lagu, ekspres, dan warna nada (1987:80). 
Unsur-unsur musik diatas juga dapat diperjelas lagi berdasarkan poin-poinnya sebagai berikut:

a. Irama Atau Ritme

Irama atau ritme adalah panjang pendeknya nada pada melodi lagu. Irama berhubungan dengan birama, karena birama menentukan nilai suatu nada pada setiap ketukan.

b. Tempo

Tempo adalah tingkat kecepatan dan lambatnya permainan musik. Sedangkan Hugh M. Miller dalam bukunya menyatakan tempo menunjukkan kecepatan di dalam musik. Adapun istilah-istilah yang umum untuk menunjukkan tempo itu di antaranya adalah : Presto (sangat cepat), Allegro (cepat), Moderato (kecepatan sedang), Andante (agak lambat), Adagio ( agak lambat dari adante), Lento (lambat), dan Largo (sangat lambat).

c. Melodi

Melodi adalah susunan rangkaian nada (bunyi dengan getaran teratur) yang terdengar berurutan serta berirama dan mengungkapkan suatu gagasan. Bunyi adalah peristiwa getaran, getaran bunyi dapat cepat dapat pula lambat. Jika suatu sumber getaran dengan cepat amaka bunyi yang dihasilkannya tinggi, umpanya bunyi gerincingan. Jika getaran bunyinya itu lambat, maka bunyi yang kedengaran rendah, umpamanya bunyi tambur besar. (2012: 15).

d. Dinamik

Menurut Kamus Musik Pono Bonoe, Dinamik merupakan keras lembutnya dalam memainkan musik, dinyatakan dengan berbagai istilah seperti: $p$ ( Piano/lembut), $f$ (Forte/keras), cresc (Cresendo/makin keras, mf (Mezzo Forte/sangat keras) dan lain sebagainya.

\section{B. METODE PENELITIAN}

Penelitian "Fungsi musik Gong Perunggu dalam Upacara Adat Kenduhai Sko Pada Masyarakat Kerinci Provinsi Jambi" menggunakan metode kualitatif. Sugiyono mengatakan Metode ini juga disebutkan sebagai metode artistik, karena proses penelitian lebih bersifat seni, dan disebut juga dengan metode interpretative karena data penelitian lebih berkenaan dengan interprestasi terhadap data yang ditemukan di lapangan. 
Suwardi Endraswara mengatakan metode kualitatif, merupakan metode sebuah pengamatan yang cenderung mengandalkan kekuatan indra peneliti untuk merefleksikan fenomena budaya. Pengamatan ini dipertimbangkan lebih akurat untuk melihat kebudayaan yang cenderung berubah-ubah seiring dengan pergeseran zaman.

Sehubungan dengan dua pendapat di atas, jelas fenomena pada "Fungsi musik Gong Perunggu dalam Upacara Adat Kenduhai Sko Pada Masyarakat Kerinci Provinsi Jambi" diteliti dengan konsep Sugiyono dan Endaswara tersebut karena Gong Perunggu adalah sebuah tradisi yang berhubungan dengan seni dan melekat erat pada batang tubuh kebudayaan Kota Sungai Penuh secara umum, serta menjadi fenomena budaya di Kota Sungai Penuh, Kerinci.

Metode kualitatif digunakan dalam penelitian "Fungsi musik Gong Perunggu dalam Upacara Adat Kenduhai Sko Pada Masyarakat Kerinci Provinsi Jambi". Secara tehnik pengumpulan data berupa data observasi, wawancara dengan pelaku seni atau pemain musik Gong Perunggu, juga masyarakat pendukung pertunjukan Gong Perunggu di Kota Sungai Penuh, selain itu menggunakan Audio dan vidio pertunjukan, serta studi pustaka dan kepustakaan terhadap penyerapan data lain sebagai pendukung penulisan.

Ketegasan dalam menggunakan metode kualitatif ini adalah sebagai pengupas fenomena tentang "Fungsi musik Gong Perunggu dalam Upacara Adat Kenduhai Sko Pada Masyarakat Kerinci Provinsi Jambi". Berdampak luas bagi pemain terutama ditujukan kepada anak muda generasi sekarang ini. Adapun pemahaman dan pengertian gejala, fakta, realita juga peristiwa yang dialami masyarakat atau manusia dari akibat budaya Gong Perunggu maka tercapai, sesuai dan terwakilkan melalui tulisan ini.

\section{PEMBAHASAN}

Iskandar Zakaria dalam Tambo Sakti Alam Kerinci 1 (1984) memberikan penjelasan tentang sejarah dan asal usul kata Kerinci, Kebudayaan Kerinci, susunan petith adat, sistem adat: sistem perkawinan, sistem rumah tangga, sistem kekerabatan, sistem kemasyarakatan, sistem pemerintahan adat, sistem hukum, dan tata cara adat Kerinci. Buku tersebut berguna sebagai acuan untuk mengungkap korelasi antara bentuk dengan adat dan agama. Bagi masyarakat Kerinci suatu kehidupan telah diatur oleh adat dan agama Islam dan tetap dipegang teguh sampai sekarang. Adat dan agama Islam 
sangat mempengaruhi masyarakat dalam berpikir, bersikap, berbuat, dan bertingkah laku. Dalam petatah adat setempat dituliskan" adat basandi syara', syara' basandi kitabullah, syara' mengato, adat memakai, syah kato syara' pakai kato adat" ( adat berdasarkan syari'at Islam, syari'at Islam berdasarkan Al-Qur'an dan Hadist, syariat Islam mengatakan, adat memakai, benar kata syari'at pakai kata adat).

Dalam memperingati acara Kenduri Sko Dusun Empih masyarakat saling membangun solidaritas dengan sistem bergotong royong dan mengumpulkan tokoh-tokoh adat untuk membicarakan acara Kenduri Sko, dalam hal ini petatah adat Kerinci mengatakan penuh semangat, rela berkorban berdasarkan prinsip kco talai dak buleh kandeu Ilahaillallah (pegangan tali kuat-kuat jangan sampai dikendurkan serta serahkan diri kepada Allah). Didalam buku tersebut juga dijelaskan dalam pembukaan acara Kenduri Sko hendaknya mendekatkan diri kepada Allah agar acara pembersihan benda-benda pusaka disertai pengokohan Depati dan rio, rio adalah nama gelar yang diberikan kepada tokoh adat, dan nenek mamak berjalan sesuai dengan janji sumpah lembaga adat. Dalam hal ini masyarakat Dusun Empih mempertahankan nilai sosial dan melahirkan suatu identitas Kenduri Sko tersebut.

Tempat pelaksanaan Kenduri Sko adalah di Umoh G'deang (rumah adat Kerinci) dengan proses upacara, musyawarah antar tokoh adat dan tokoh masyarakat untuk menentukan jadwal pelaksanaan acara Kenduri Sko tersebut. Didalam penyelenggaraan musyawarah adat yang dimaksud masyarakat Dusun Empih tidak hanya masyarakat saja yang mengadakan Kenduri Sko melainkan perizinan tokoh-tokoh adat lainnya. Tanpa adanya tokoh adat lainnya maka tidak bisa Dusun Empih melaksanakan Kenduri Sko. Begitulah adat yang mengikat masyarakat agar saling bahu membahu saling bergantungan dengan sesama lain. Duduk mempunyai aturan derajat sesuai dengan jabatan adat, berbicara tidak bisa sembarangan mempunyai aturan-aturan adat. Lihat gambar di bawah ini: 


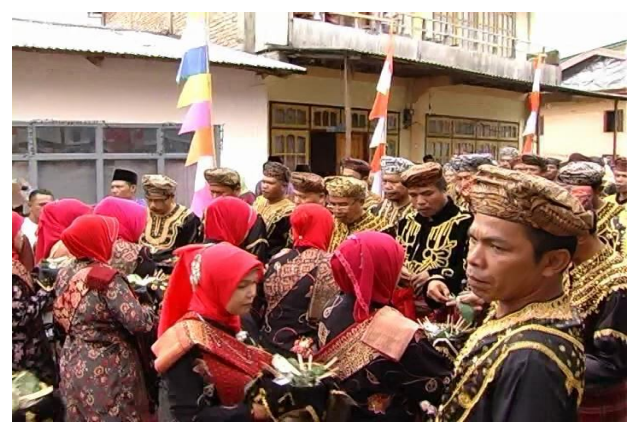

Gambar I

Ngejon arah, pemukulan Gong Perunggu, dan Penobatan Gelar disambut dengan anak batino (wanita) di tengah laheh (dusun)

(Dokumentasi: Deria Sepdwiko 12- -2013)

Adat yang dipakai memiliki orang yang dipercaya sebagai pelaksana adat yang disebut dengan pemangku adat, di Sungai Penuh para pemangku adat disebut dengan Depati, Ninik Mamak dan Permenti, yaitu Depati nan bertujuh, pemangku nan berdua dan permenti nan sepuluh. Depati dan Ninik Mamak adalah orang yang berfungsi untuk mengurus anak jantan (laki-laki) dan anak batino (wanita) dalam negeri, menyelesaikan yang kusut dan menjernihkan yang keruh. Sedangkan permenti berfungsi untuk mengurus organisasi dan pemerintahan.

Dalam pelaksanaan upacara Kenduri Sko masyarakat bersama-sama menuju ke rumah adat untuk melakukan ritual beserta sesajen yang telah disiapkan anok betino (anak perempuan) sebagai kelengkapan dari upacara. Sesajen ini harus disepakati oleh lembaga adat dan tidak bisa sembarangan orang yang melengkapi sesajen tersebut. Dalam hal ini sesajen yang dimaksud adalah berupa bunga, kemudian mangkok kecil yang berisikan beras dan dilengkapi sirih yang digulung beserta rokok lipah, pinang seikat, pisang, minyak yang di campur dalam air disatukan dalam baskom sebagai tempat pembersihan dan pemandian benda-benda keramat yang nantinya akan dibersihkan oleh orang yang dituakan, serta kemenyan sebagai persyaratan pembukaan Kenduri Sko. Lihat gambar di bawah ini: 


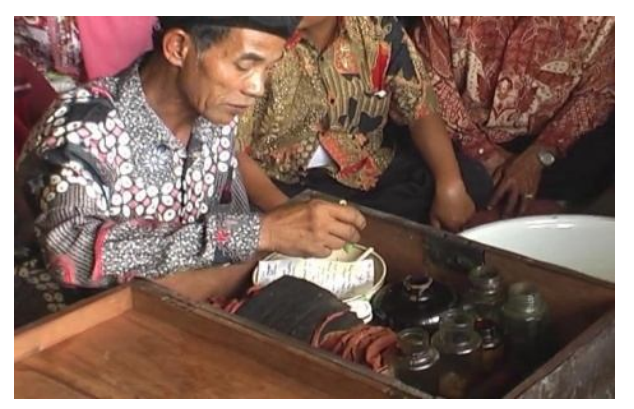

Gambar II Pembacaan mantera pembersihan benda-benda pusaka

(Dokumentasi: Deria Sepdwiko 2 Februari 2012).

Pada kesempatan ini penulis mencoba meneliti alat musik Gong Perunggu berdasarkan kajian Musikologis, sebagai suatu usaha pendokumentasian penginventarisasian alat musik Gong Perunggu dalam upacara Kenduhai Sko pada masyarakat Sungai Penuh Provinsi Jambi. Hal ini dilakukan agar tidak mengalami kepunahan dan dapat diperkenalkan pada masyarakat luas terutama masyarakat akademis untuk masa sekarang dan akan datang. Disamping itu juga diharapkan agar dapat di lestarikan nantinya, dengan usaha tersebut alat musik Gong Perunggu agar dapat di kenal sebagai milik nasional.

Adapun fungsi musik dalam pertunjukkan upacara Kenduhai Sko, Gong Perunggu adalah sebagai media penghubung atau komunikasi roh leluhur dan masyarakat setempat, dengan dunia spiritual yang mana dalam hal ini masyarakat melakukan komunikasi terhadap roh-roh leluhur agar roh-roh leluhur mampu menjaga dusun Empih. Musik Gong Perunggu ini juga berfungsi sebagai pengiring tari Asyek dan silat sambil sipelaku memulai aksinya yang mana si pelaku sudah tidak lagi berprilakuan seperti manusia normal tetapi berprilaku seperti roh-roh leluhur yang merasukinya.

Di dalam pertunjukkan ini musik juga memiliki tingat kesakralan, unsur-unsur musik pada umumnya, irama/ritme selalu di ulang-ulang, dalam pukulan tersebut mengandung makna tingkat kesakralannya terhadap roh leluhur dan menjadikan suatu kedekatan emosionalnya terhadap leluhur.

a. Irama/Ritme

Irama atau Ritme adalah panjang pendeknya nada pada melodi lagu. Irama berhubungan dengan birama, karena birama menentukan nada pada setiap ketukan. Pola 
ritme dalam pemukulan hanya pengulangan itu-itu saja bersifat monoton. Untuk lebih jelasnya dapat di lihat pada pola irama pukulan berikut ini :

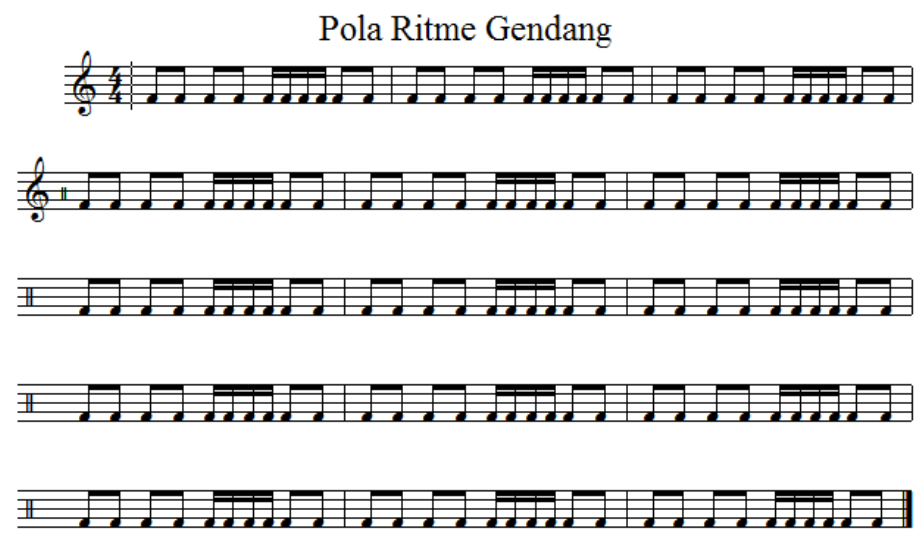

Notasi 1

\section{Pola Gendan Katindik}

Di sinilah nampak jelas kesederhanaan musik dalam upacara Kenduhai Sko mencerminkan sebagai musik tradisional pedesaan yang masih hidup dan berkembang dalam pola pelembagaan ritual adat. Kesederhanaan pola ritme maupun melodi itu tidak terlepas dari tujuan musik Gong Perunggu dilaksanakan sebagai sarana untuk berhubungan dengan roh nenek moyang mereka.

b. Melodi

Melodi adalah susunan rangkaian nada (bunyi dengan getaran teratur) yang terdengar berurutan serta berirama dan mengungkapkan suatu gagasan. Bunyi adalah peristiwa getaran, getaran bunyi dapat cepat dapat pula lambat. Jika suatu sumber getaran dengan cepat amaka bunyi yang dihasilkannya tinggi, umpanya bunyi gerincingan. Jika getaran bunyinya itu lambat, maka bunyi yang kedengaran rendah, umpamanya bunyi tambur besar. (2012: 15). 


\section{MELODI GONG PERUNGGU}

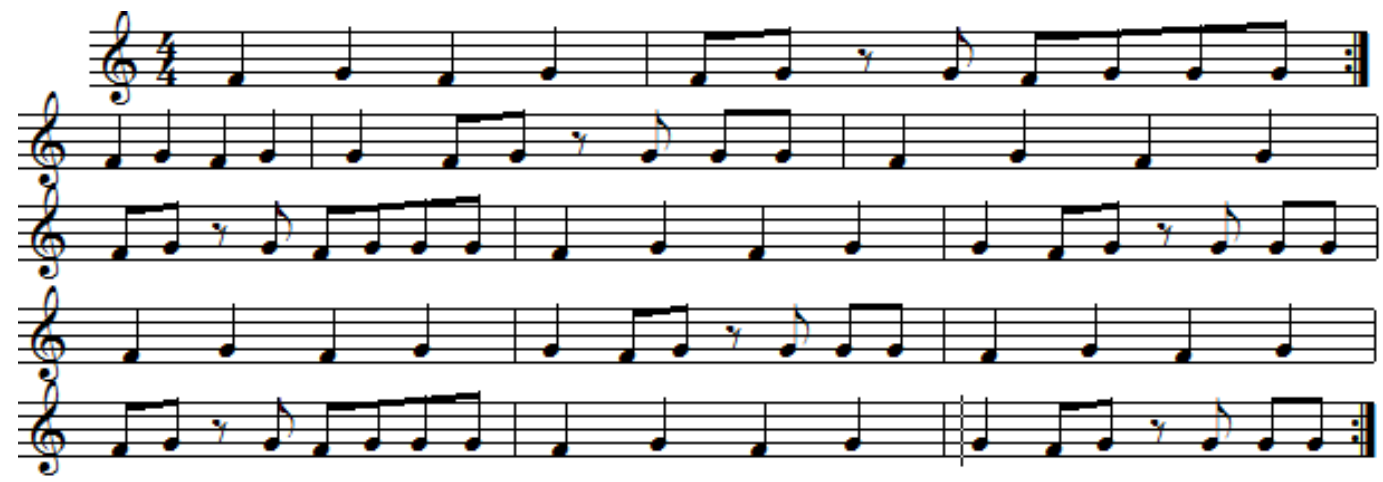

Notasi II

Melodi dua buah Gong Perunggu

Pesan yang disampaikan di dalam satu ketuk bunyi Gong Perunggu adalah mengungkapkan arwah orang tua dahulu. Memiliki kedekatan hubungan roh seperti memanggil malaikat, arwah orang tua, arwah nenek moyang di yang ungkapkan melalui bunyi Gong Perunggu tersebut. Ada tujuh macam arwah di dalam kekuatan bunyi gong yaitu: (1) arwah orang muda memiliki isi, (2) arwah orang yang bingung mempunyai isi, (3) arwah yang masuk kedalam orang sawan/sakit-sakit terdengar bunyi gong mempunyai semangat untuk berobat, (4) apabila terbunyi gong yang berdengung suatu panggilan batin untuk datang ke upacara Kenduhai Sko, (5) arwah nenek moyang memiliki istilah tujuh kapela langit tujuh kepala bumi, (6) arwah tujuh didalam awan, tujuh didalam angin, kemudian (7) arwah yang merasuki ke dalam diri dukun/pawang dalam pengucapan upacara Kenduhai Sko.

\section{c. Dinamik}

Menurut Kamus Musik Pono Bonoe, Dinamik merupakan keras lembutnya dalam memainkan musik, dinyatakan dengan berbagai istilah seperti: $p$ ( Piano/lembut), $f$ (Forte/keras), cresc (Cresendo/makin keras, mf (Mezzo Forte/sangat keras) dan lain sebagainya.

Dinamik yang terdapat pada bunyi Gong memiliki kedekatan terhadap roh nenek moyang yang berupa sahabatnya seperti jin, jin yang di dalam adalah berupa: "jin Islam", "jin bunto beraut", "jin tanjo beraout", "jin tanjo bumi". Disaat bunyi Gong sebagai perizinan 
adat maka arwah-arwah nenek moyang selalu membawa sahabatnya pada ritual pembersihan benda-benda pusaka. arwah-arwah nenek moyang akan merasuki kedalam tubuh orang yang merupakan garis keturunannya, akan terlihat pada pembersihan bendabendapusaka. Menunjukkan bahwa roh nenek moyang selalu tetap menjaga tanoh mendapea (dusun), tempat kelahiran nenek moyang. Kedekatan arwah roh nenek moyang dengan anak cucunya begitu dekat, terlihat dalam pensucian musik Gong Perunggu dan Gendang. Lihat gambar di bawah ini:

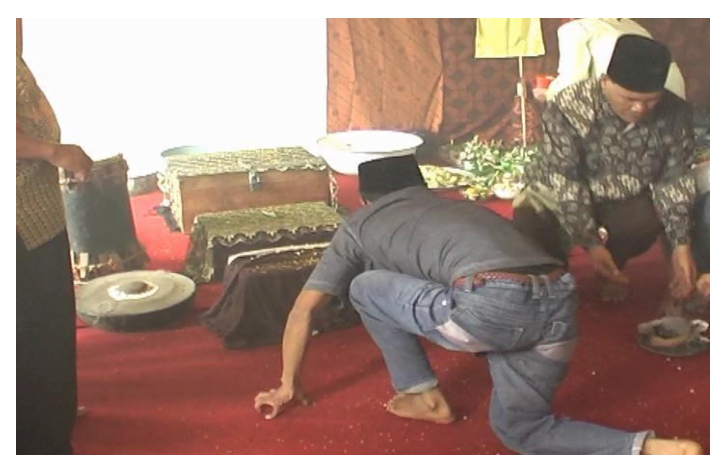

Gambar III Saat pensucian Gong Pereunggu (jenis Gong berpencu terbuat dari perunggu) gendang, dan benda pusaka lainya dirasuki oleh roh nenek moyang

(Dokumentasi: Deria Sepdwiko 12- Juni -2013)

\section{SIMPULAN}

Upacara Kenduri Sko diadakan kurang lebih sepuluh tahun sekali dan menampilkan berbagai kesenian-kesenian tradisi dari daerah Dusun Empih. Dari fenomena budaya tersebut melahirkan suatu kekhasan budaya yang merupakan hasil peninggalan nenek moyang mereka. Selain fenomena budaya yang telah dipaparkan, keadaan yang melekat pada Gong Perunggu juga menjadi faktor ketertarikan dan ketakakutan akan pelestarian musik Gong Perunggu dengan rentan waktu yang kian lama, dengan hadirnya penelitian tentang musik Gong Perunggu menjadi suatu nilai timbul balik bagi masyarakat dan bagi penulis setidaknya membawa dampak positif agar musik Gong Perunggu tetap dilestarikan menjadikan arsit budaya cerminan khas tradisional Kerinci.

Dengan demikian fenomena budaya tersebut melahirkan suatu kekhasan budaya yang merupakan hasil peninggalan nenek moyang mereka dan menjadi faktor ketertarikan 
penyaji untuk mengangkat hal tersebut sebagai kajian ilmu musikologis. Selain itu nada musik gong dan perkusi memiliki pesan yang mendalam bagi masyarakat Dusun Empih, adapun orang yang memainkan sekaligus mendengar memiliki makna kesakralan dalam memainkan Gong Perunggu, begitu juga tempo yang konstan dan musik yang dilahirkan memiliki kekhasan tradisional yang bersifat berulang-ulang tanpa ada perubahan siklus baik disegi nada maupun bunyi perkusinya. Sehingga mengandung berbagai fenomena yang layak untuk di ungkapkan dan dibedah.

\section{DAFTAR PUSTAKA}

Adirozal, 2013. Model Pendidikan Seni Ukir Pada Sanggar Tradisional Pandai Sikek Kabupaten Tanah Datar, Disertai,. (Padang:Universitas Negri Padang).

Agusa Salim, 2006. Teori dan paradigma penelitian sosial (Yogyakarta: Tiara Wacana

Alan P. Merriam 1980. The Antropology of Musik (Northwestern: University Press).

Alan P. Merriam, 1964. The Anthropology of Music (Chicago: Northwestern University Press.).

Farida, 1997. Tinjauan Organologis dan Musikologis Talempong Batu: Studi kasus di Desa Talang Anau Kecamatan Gunung Mas Kabupaten 50 kota Skripsi; (Padang: IKIP Padang).

Hamka, 1984. Islam dan Adat Minangkabau. Jakarta: Pustaka Panji Mas.

Iskandar Zakaria dalam Tambo Sakti Alam Kerinci 1 (1984).

Julia Brannen, 2005. Memandu Metode Penelitian Kualitatif dan Kuantitatif (Samarinda: Pustaka Pelajar).

Janet Wolff. 1981The Social Production of Art (New york: St. Martin's Press,) 
Julia Brannen. 2005. Memandu Metode Penelitian Kualitatif dan Kuantitatif (Samarinda: Pustaka Pelajar).

Sugiyono, 2008. Metode penelitian Pendidikan (Bandung: Alfabeta)

Suwardi Endraswara, 2006. Metodologi penelitian kebudayaan (Yogyakarta: Gajah Mada University Press).

Y. Sumandiyo Hadi, 2006. Seni Dalam Ritual Agama (Yokyakarta: penerbit Buku Pustaka).

Hadi, Y. Sumandiyo. 2006. Seni Dalam Ritual Agama (Yokyakarta: penerbit Buku Pustaka).

Hamka. 1984. Islam dan Adat Minangkabau. Jakarta: Pustaka Panji Mas. Iskandar Zakaria dalam Tambo Sakti Alam Kerinci 1. 